\title{
The case of successful thrombolysis in early postoperative period of the extended thyroidectomy
}

\begin{abstract}
Pulmonary thromboembolism is a life-threatening complication of early postoperative period. The patients undergoing cancer operation have increased risk of it. The treatment of thromboembolism in this unstable period is quite complicated. The thrombolysis is under concern and officially contraindicated in the most of the cases. Here we present the successful clinical case of thrombolysis after thyroidectomy, complicated with pulmonary thromboembolism.
\end{abstract}

Keywords: thromboembolism, bleeding, blood cell-save technology
Volume 3 Issue I - 2018

\begin{abstract}
Ahmetzanov F Sh, ${ }^{1,2}$ Shaymardanov IV, ${ }^{1,2}$ Pasheev AV, ${ }^{1,2}$ Sayetgaraev AK,' Hasanov AF' 'Tatarstan Regional Clinical Cancer Center, Russia ${ }^{2}$ Kazan state medical academy, Russia
\end{abstract}

\author{
Correspondence: Dr. Pasheev AV, Department Tatarstan \\ Regional Clinical Cancer Center,Assistant of the Anesthesiology \\ and Intensive Care Department, Kazan state medical academy, \\ Russia,Tel (843)519-26-31; +7-927-674-46-80, \\ Email artur.pasheev@yandex.ru
}

\section{Introduction}

The female patient, mrs.Sh. 44 years old, admitted to the Tatarstan Republican Clinical Cancer Center to the Head and Neck surgery department on 19.09.2017. She has got the Papillary Thyroid Cancer with metastasis to pre-tracheal and para-tracheal lymph nodes. The thyroidectomy with central and both lateral cervical and supraclavicular lymphadenectomy was performed on 20.09.2017 under general anesthesia without any technical difficulties. The duration of the operation was $2 \mathrm{~h} 45 \mathrm{~min}$. The patient gained consciousness and was extubated in $35 \mathrm{~min}$ after the end of the operation in the intensive care unit. Then, she was transferred to the Head and Neck department under supervision of the surgeon. According to the guideline, the preventive measures to avoid thromboembolic were taken. The compressive stockings were put on for intra- and post- operative periods. Injections of low-molecular enoxaparin in the dosage of $40 \mathrm{mg}$ started in 8 hours after the end of the operation, when there was no danger of bleeding. Preoperative injection of enoxaparin didn't perform because of the features of the operations. The lymph nodes lied close to the carotid arteries brachiocephalic truncus. There was the danger of unintended damage of the vessels. The earliest postoperative period on the day of the operation was quite. The patient took the sitting position, started drinking and eating.

On the next day, at the day time, she felt progressive dyspnea. She was transferred to the intensive care department, where the suggestion of acute lung artery thromboembolic was taken, taken into account the character of dyspnea and extremely low level of blood saturation $60 \%$, with weak response to oxygen therapy. The suggestion was approved by the chest tomography, where the thrombosis of both central lung arteries was revealed (Figure 1-4). After the short discussion among the colleagues, the procedure of thrombolysis was performed. We considered the extremely bad condition of the patient, weak response to oxygen therapy, young age and a kind of the operation. There were no pass to any cavity, no anastomosis, the inserted drainage system, to let blood flow out. Additionally, we had blood cell-save machine "Haemonetics Cell Saver 5+" (USA) to reinfuse blood and decrease blood loss.

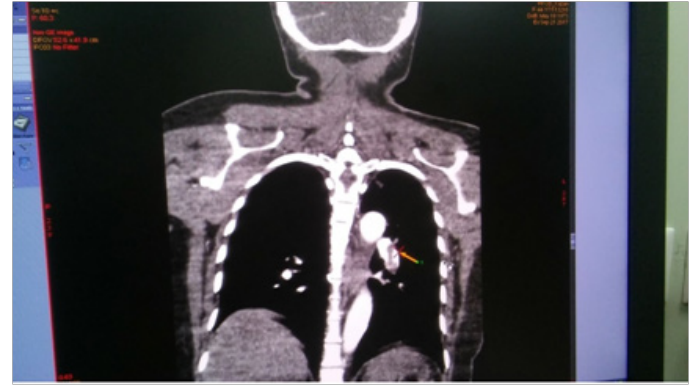

Figure I (CT of thromboembolism in the left LA).

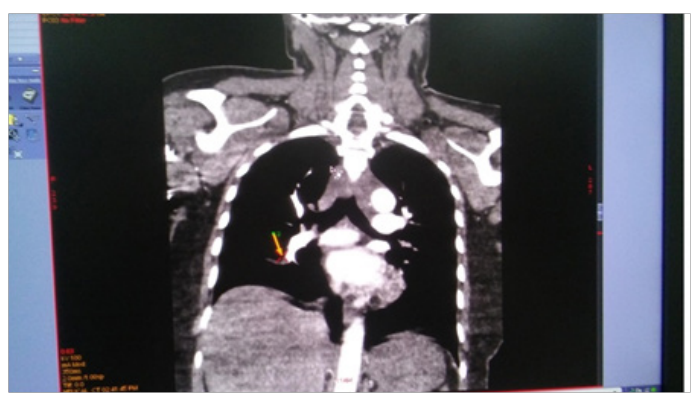

Figure 2 (CT of thromboembolism in the right LA).

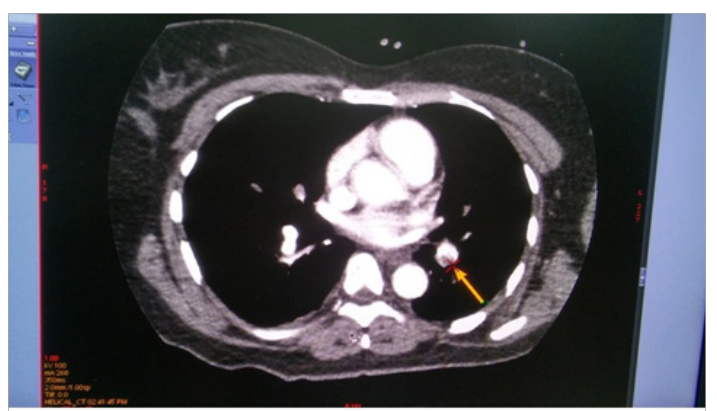

Figure 3 (CT of thromboembolism in the left LA) 


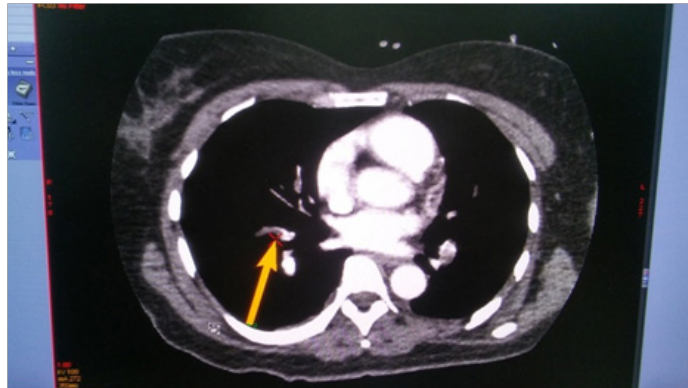

Figure 4 (CT of thromboembolism in the right LA).

Alteplasa, in dosage of $100 \mathrm{mg}$, was infused for two hours, follow the instruction. The patient felt relief and decrease of dyspnea. Unfortunately, we got the severe bleeding from the neck drainage. The cell saver machine was connected to drainages and began to reinfuse blood to the pre-installed catheter in the right femoral vein. In sum, we reinfused $1080 \mathrm{ml}$ of blood, transfused symptomatically $940 \mathrm{ml}$ of allogenic blood cells and $1640 \mathrm{ml}$ of fresh frozen plasma. In about 5 hours after the beginning of the thrombolysis the bleeding stopped. On the second postoperative day, the patient condition became steady. The control tomography showed no thrombosis in the lung arteries (Figure 5) (Figure 6). Meanwhile, the ultrasound investigation revealed thrombosis in the left shin veins that could be the source of the thromboembolism. Besides, the postoperative wound swelled and the patient felt suffocated. She was taken to the operative theater for revision and performing tracheostomy under general anesthesia. The indication for tracheostomy was a progressive pressure of the soft neck tissues to the trachea, led to strangulation.

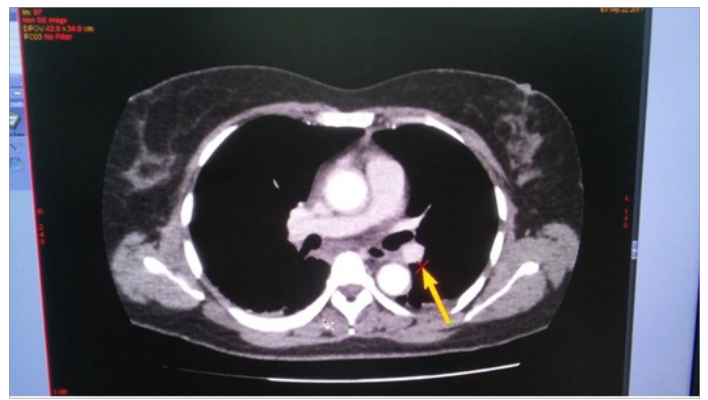

Figure 5 (CT after thrombolisis).

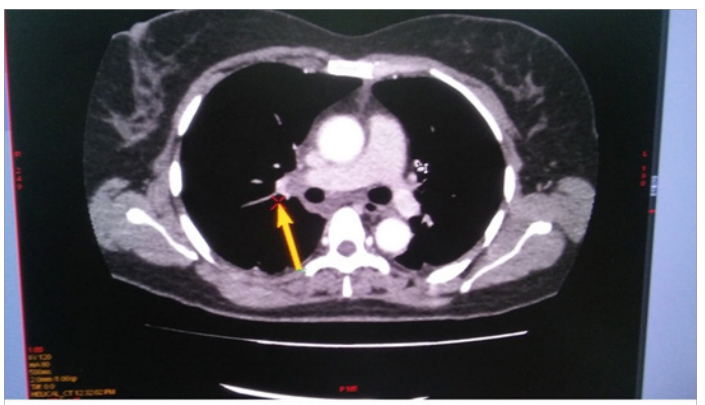

Figure 6 (CT after thrombolisis).
After the second operation, the patient condition was stable. She got the permanent infusion of heparin in dosage of $1000 \mathrm{ME} /$ per hour through a pump under active coagulation time control for two days. Then, after the consult of vessel surgeon, heparin therapy was substituted to the oral uptake of rivaroxoban in a dosage of $30 \mathrm{mg}$ for the 3 weeks and $20 \mathrm{mg}$ for 6 months further. The tracheal tube was taken of in five days after tracheotomy. The patient discharged from the hospital in 16 days after the first operation. The approach to the treatment of the lung thromboembolism in the early postoperative period is quite discussable. ${ }^{1-4}$ Meanwhile the thrombolysis is not recommended in this period, this is the only chance to survive for the patients. In our opinion, in condition of using blood cells save technologies, it is possible.

\section{Conclusion}

i. The oncological patient undergoing surgical operations have high risk of thromboembolism.

ii. The preventive measures must be obligatory.

iii. The preoperative ultrasound investigation can reveal thrombosis in low extremities veins.

iv. Thrombolysis in the early postoperative period is possible with assistance of blood cell saving technologies.

\section{Acknowledgements}

Assistance with the study: we would like to thank Dr. Sharafutdinov Rinat, Sadykov Kamil and Kamalov Ilfak for support and advice during procedure.

\section{Conflicts of interest}

The author declares no conflict of interest.

\section{References}

1. British thoracic society standards of care committee pulmonary embolism guideline development group. british thoracic society guidelines for the management of suspected acute pulmonary embolism. Thorax. 2003;58(6):470-483.

2. Jaff MR, McMurtry MS, Archer SL, et al. Management of massive and submassive pulmonary embolism, iliofemoral deep vein thrombosis, and chronic thromboembolic pulmonary hypertension:a scientific statement from the American heart association. American heart association. Circulation. 2011;123:1788-1830.

3. Kadner A, Schmidli J, Schönhoff F, et al. Excellent outcome after surgical treatment of massive pulmonary embolism in critically ill patients. J Thorac. Cardiovasc Surg. 2008;136:448-451.

4. Aymard T, Kadner A, Widmer A, et al. Massive pulmonary embolism: surgical embolectomy versus thrombolytic therapy- should surgical indications be revisited? Eur J Cardiothorac Surg. 2013;43(1):90-94. 